Revista de Antropología Social

ISSN: 1131-558X

http://dx.doi.org/10.5209/RASO.61863

\title{
Mojón reflexivo: sobre salud intercultural desde y más allá de lo antropológico
}

Gil García, Francisco M.; Vicente Martín, Patricia (Coords.). 2017. Medicinas y cuerpos en América Latina. Debates antropológicos desde la salud y la interculturalidad. Quito: Abya-Yala.

Abya-Yala, editorial y continente, habilita una vez más narrativas sobre salud intercultural: ocho trabajos específicos, pero aunados conceptualmente y armónicos teórica e ideológicamente, de modo que ensayaremos una reseña acorde.

En América Latina las problemáticas sanitarias parecieran ser siempre urgentes y actuales, y «lo intercultural» es crucial, pero también solo parte de un conjunto de factores que actúan sinérgicamente en el arduo camino hacia, en definitiva, el bienestar social. Si bien es factible atribuir a cada gobierno actuaciones particulares, y contextualizar históricamente cada país, lo cierto es que la estatalidad capitalista -estructural y estructurante- deja escaso margen ante, por ejemplo, la revitalización del extractivismo ${ }^{1}$ y la expoliación transnacionalizada o la agenda de los organismos internacionales ${ }^{2}$, todo lo cual condiciona la salud de los pueblos. Los autores de este volumen son conscientes de esto y, por ende, de la articulación y el solapamiento de lo intercultural con lo económico, lo político, lo ecológico y lo social, pero también lo demográfico y epidemiológico; «la clase» y «la Nación», pero también «el género» y «lo corporativo». Y es que la otredad es inherente a la hegemonía: esta y aquélla indefectiblemente adquirirán múltiples expresiones. Así, solo por caso, la soberbia legítima de lo biomédico en general y la corporación médica en particular, podría implicar que todos los cuerpos sean pasibles de violencia, no solo los indígenas.

En esta misma línea argumental es que apuntamos como uno de los ejes transversales del libro, la figura del Estado-Nación. Paradójicamente, quien en el sendero de su consolidación no solo fuera artífice de los procesos de exclusión, subalternización $^{3}$ e invisibilización de las comunidades originarias, sino que además coadyuvara en la «universalización de la biomedicina y la homogeneización de lo patológico»", se erige como potencial garante de la salud intercultural. Es el Estado el que, en el marco de decidir planificar, ejecutar y jerarquizar la salud pública, adquiere la

1 Forma puntual de extracción de los recursos naturales en la que se cumplen simultáneamente tres condiciones: un alto volumen y/o intensidad en la extracción -alto impacto sobre el medio ambiente-, tratarse de recursos sin procesar o con escaso procesamiento, y donde se exportan el 50\% o más de esos recursos (Gudynas, 2015).

2 Por ejemplo, en pos de la implementación de sistemas de aseguramiento -como los ya aplicados en México o Colombia- y no de aquellos universales que procuren una - utópica/retórica- «salud para todos».

3 Esta categoría es de uso extendido en los estudios sobre comunidades indígenas en América Latina y refiere al proceso mediante el cual los Estado-Nación lograron que los grupos indígenas se convirtieran en sectores subordinados, vía la derrota militar, pero también a través de la deslegitimación de su control territorial y la inviabilidad como sociedad al interior de las naciones; esto en base a considerarlos extintos (Salomón Tarquini, 2011).

4 Concepto esgrimido en el capítulo escrito por Javier Rodríguez Mir en la obra aquí reseñada. Con la correspondiente anulación de las culturas médicas en un doble sentido: reemplazo de lo cultural por lo biológico en los procesos de salud-enfermedad y en función de la anulación de la convivencia y/o superposición de los modos médicos indígena y occidental. 
capacidad de asegurar el respeto de lo intercultural y en este sentido de regular los modos y el impacto del accionar médico, pero también de estimular su formación intercultural y dignificar su rol material y simbólicamente; de diagramar y financiar programas y solventar instituciones adecuados. Esta es una de las preocupaciones de quien coordinara los emblemáticos cinco volúmenes sobre Salud e Interculturalidad en América Latina, Gerardo Fernández Juárez, que en «Sin Raulito no hay salud intercultural; Etnografía y trabajo de campo en el altiplano de Bolivia», «aventura un pequeño muestrario de recomendaciones para los equipos de salud que trabajan en comunidades indígenas». En lo que podría rotularse como un ejercicio multidireccional de otredad, el autor procura comprender no solo los pesares y sentires del indígena sino también del agente biomédico, a la vez que deja al desnudo las transformaciones del antropólogo en su interactuar y construir socialmente en una arena dilemática y grotescamente ética como la salud.

En «Interculturalidad en salud; dudas, limitaciones y repliegues», Eduardo Menéndez, uno de los primeros graduados en antropología en la UBA-Argentina-, residente en México desde los inicios de la dictadura, expone algunos de los factores que considera causales del fracaso de las principales propuestas interculturales. El autor hace hincapié en el error de lo sincrónico, ya que, por un lado, las comunidades indígenas son interpeladas con foco en lo estático, en las permanencias y, por el otro, los programas interculturales del nuevo milenio se implementaron haciendo caso omiso de experiencias precedentes. La homogeneización -que también es estereotipación-impediría observar, entre tantas cuestiones, la diversidad -y los conflictos-intracomunitarios, la penetración de la biomedicina en la cotidianidad indígena y la biomedicialización de los curadores tradicionales o la presencia de enfermedades alopáticas en un indígena romantizado, solo portador de diferencias y cosmovisiones. Así, parte de la distancia entre las expectativas y los resultados de las propuestas interculturales se explicaría por la intelectualización en su génesis y su unidireccionalidad en la práctica.

Francisco Gil García aporta «Apuntes para una etnografía del medicamento», que exhibe su ineludible carácter social mediante un análisis en si del «remedio como fetiche y del fetichismo del remedio», a la vez que para abundar en la complejidad de lo intercultural, que sugiere leer como «bricolaje sanitario» y no en clave de imposición-rechazo. El caso del proverbial Mentisán es solo una de las expresiones ejemplificadoras de lo antedicho tomadas por el autor: posesión y apropiación, pero también conjunción de saberes, variedad de aplicaciones, intersecciones étnicas o «racionalidad mestiza», que deberían inducir abordajes contextuales en torno a un objeto en lugar de aquellos excluyentes como respuesta a tipos ideales. En este timo incurre el etnógrafo, que con su sola presencia y mandato interpretativo instala una incoherencia entre el discurso y la praxis de las comunidades observadas, allí donde en definitiva hay vivencia y sobrevivencia en un devenir socio-cultural enrevesado. Sobre esto escribe Oscar Muñoz Morán en sus «Lógicas interculturales y discursos contradictorios», al explicar el uso de las medicinas por parte de una comunidad de Copaisi -Bolivia-, acto prácticamente compatible y teóricamente sancionable a la luz de la perspectiva mencionada y que evidentemente condiciona a los mismos indígenas que en ocasiones escogen manifestarse en términos puristas.

En «Hambrientos y desnutridos en el oriente de Guatemala; dificultades y aprietos biomédicos para una atención intercultural en salud», Lorenzo Mariano Juárez desafía al lector no avezado a ensayar una mirada cultural y relativista sobre una materia «tan aparentemente biológica y universal como la de la desnutrición». Así, 
la etiología de dicha enfermedad y, por ende, las decisiones indígenas en cuanto a remedios y soluciones, no necesariamente se asociarán a la falta de alimentos adecuados y al balance calórico, como indicaría la postura biomédica. Una operación comprensiva similar es imprescindible cuando Patricia Vicente Martín expone en «Tablas estadísticas y cuerpos invadidos; apuntes sobre el aborto en Bolivia y en Sudamérica», una aproximación etnográfico-complejizadora de una práctica como el aborto, signada por el análisis cuantitativo. Si bien aquello supuestamente «objetivo» de la desnutrición se desvanece con un tópico como el aborto que presiona sobre tantas fibras sensibles, cierto es que a nadie se le hubiera ocurrido dudar de los habituales exámenes estadístico-racionales. La autora lo hace, puntuando las falencias metodológicas de estas aproximaciones derivadas de la clandestinidad de esta práctica o del no cumplimiento del ideal normativo de ciertos países, pero fundamentalmente del copioso entramado cualitativo que sostiene y oficia de entretelón de aquellos números y los vuelve incompletos y falaces. En el caso de las comunidades indígenas, a los condicionantes religiosos, éticos, morales, sociales o de género, es preciso adjuntar percepciones y acciones de origen comunitario, aún más soslayados que aquellos por el investigador occidental.

«Salud e interculturalidad; reflexiones a partir de la experiencia en un programa de cooperación al desarrollo en la Amazonía ecuatoriana», de Montserrat Pulido Fuentes, actualiza la prepotencia de las agencias internacionales y su pintoresca categorización del imperialismo: «agentes de desarrollo», «promotores de salud», que bajarían al campo con una intención mediadora y respetuosa de la diversidad para sustancialmente ser actores de aculturación, de una normativización y una reglamentación biomédica. Lo local-tradicional es considerado, pero conservando la asimetría, la jerarquía e intimidación del modelo dominante.

Finalmente, en «Apropiación de pacientes, saberes y poderes; una perspectiva crítica desde la antropología de la salud en la región del Chaco», Javier Rodríguez Mir reposa en la espacialidad del Gran Chaco sudamericano para vislumbrar algunas de las consecuencias de la consolidación republicana en lo intercultural de la salud: de lo que parecía ser la anulación total de las medicinas indígenas, a su sobrevivencia y resignificaciones; de lo positivo de la reemergencia indígena en los 90 y su materialización legal o simbólica, a la crudeza de problemáticas como la desnutrición, irrisoriamente no resueltas en el nuevo milenio.

Metodología, teoría, tema, actitud, proceso, herramienta, habilidad, moda, retórica excesiva, horizonte utópico/utopía bienintencionada, fetiche, necesidad técnica, palabra mágica, concepto políticamente correcto, son algunas de las formas en las que cabría referirse según los autores a lo intercultural en general y a la salud intercultural en particular. Definir, sin encasillar; rotular para comprender y actuar, sin estigmatizar ni juzgar, podría consignarse. Teoría y práctica se definieron gradual y dialécticamente; lo urgente aceleró lo existente y, así, terreno/territorio e intelectualidad construyeron y/o consolidaron un campo que en un contexto de reemergencia indígena no pudo más que sobresalir tanto en las autorepresentaciones como en las agendas públicas 5 . Pero este libro está de vuelta. Allí donde algunos rezagados aún

En Argentina fue a partir de la emergencia del cólera en -qué ironía- 1992 que «la cobertura de los servicios de salud en las comunidades indígenas adquirió resonancia pública [...] y el estado de salud de la población indígena ingresó paulatinamente en los ámbitos de gestión como asunto que debía ser atendido». La «conformación de una red de agentes sanitarios indígenas» fue una de las bases del enfoque intercultural en salud (Casali, 2017. Entrecomillado de Lorenzetti 2017). 
anclamos en las certezas semántico-conceptuales de la salud intercultural, constitutivas en parte del apogeo antedicho, los trabajos aquí compilados se erigen más o menos conscientemente como ejercicio reflexivo desestabilizador. Los autores se escudan en sus trayectorias, en experiencias pasadas -algunas más pretéritas que otras-, y conjugan un exquisito relato cotidiano -vivo, emotivo--, con una narrativa profesional tan autocrítica como propositiva. Vivencias recuperadas para argumentar un estado del arte, una autoconciencia intelectual tan vacilante como optimista en la teorización y en la acción. Los autores disponen huir del narcisismo antropológico y evadir todo romanticismo, consecuentemente con la no estereotipación y subestimación de los participantes en los procesos.

En diversa medida y en función de diferentes ítems, todos los trabajos del volumen concilian la labor etnográfica con la teorización y reflexión sobre la salud intercultural; complejizan sus actores y agentes, sus principios y sus componentes, sus aciertos, falencias, vicios y ventajas. Todas las medicinas y todos los médicos son tan necesarios como falibles, del mismo modo que los bloques «indígena» y «occidental» no deben aprehenderse como tales, en sí sino en relación inter e intra, como totalidad y como parcialidad, como entidades mutables sincrónica y diacrónicamente, como la identidad misma. Una vez más, la laxitud de «lo social» es aprehensible como potencial eje, plataforma o marco; como se lo mire o como se lo necesite para potenciar el imprescindible enfoque relacional e inexcusablemente holístico.

América Latina sabe de matrices capitalistas, pero también de recrudecimientos neoliberales en los que el capital no cesa de producir otros y en los que las agencias internacionales aguzan su astucia discursiva legitimadora: de unos 90 con pintorescos indígenas y multiculturalidades fragmentadoras, a bárbaros, atrasados, terroristas antisistema en un milenio de recursos agotados y ambientalistas asesinados. Es un anhelo ético básico que el proceso de visibilización indígena no se revierta y que allí donde hubo conquistas, las posverdades de la actual derecha democrática no pugnen por un retroceso. La mirada intercultural es primordial y constitutiva de este deseo.

\section{Romina Casali Consejo Nacional de Investigaciones Científicas y Técnicas (CONICET). Argentina romina.casali@gmail.com}

\section{Referencias bibliográficas}

Casali, Romina (2017). Introducción al dossier «Enfermedades y colonialidad. Poder y salud en situaciones de contacto interétnico en la América meridional». Revista de Estudios Maritimos y Sociales, 11: 3-33.

Gudynas, Eduardo (2015). Extractivismos. Ecología, economía y política de un modo de entender el desarrollo y la naturaleza. Cochabamba: CEDIB.

Lorenzetti, Mariana (2017). «Los enfoques de salud intercultural en los ámbitos de gestión e investigación en Argentina». Revista de Estudios Marítimos y Sociales, 11: 148-176.

Salomón Tarquini, Claudia (2011). «Procesos de subalternización de la población indígena en Argentina: los ranqueles en La Pampa, 1870-1970». Revista de Indias, vol. LXXI, núm. 52: 545-570. doi:10.3989/revindias.2011.018 